Now published in a Book Symposium on John Martin Fischer, Our Fate, in European Journal for Philosophy of Religion, Vol. 9, No. 4 (2017), pp. 39-50. Doi: 10.24204/EJPR.V9I4.2028

\title{
Fischer and the Fixity of the Past
}

\section{PENELOPE MACKIE}

\section{Introduction}

This excellent collection, Our Fate: Essays on God and Free Will, brings together eleven of John Martin Fischer's previously published papers, together with a fascinating 50-page introductory essay in which Fischer not only summarizes and elaborates the content of the papers, but also develops further important arguments concerning divine foreknowledge and human freedom and moral responsibility. As well as being a major contribution to the philosophy of religion, its interest and importance extends well beyond that sphere, notably to issues concerning the compatibility of free will and causal determinism, the asymmetry between past and future, the evaluation of counterfactuals, varieties of dependence, and the nature of knowledge. In this short essay, my focus will, however, be limited to one of the book's major themes: the fixity of the past.

In a series of papers, many of them included in Our Fate (OF), ${ }^{1}$ and in his book The Metaphysics of Free Will (1994), Fischer has discussed, elaborated, and defended a principle that he calls 'The Fixity of the Past' (henceforth 'Fixity Principle'). The guiding idea of this principle is that our freedom is restricted to the freedom to add to the given past; alternatively, that anything that we can do is a possible extension of the actual past.

If the Fixity Principle is true, it rules out any view according to which we may have the ability to do otherwise even if our doing otherwise would require a different past from the actual past. ${ }^{2}$ Not all versions of compatibilism are committed to this claim. Nevertheless, the varieties that are relevant to Fischer's Fixity Principle include not only versions of

\footnotetext{
${ }^{1}$ To refer to the papers in this collection, I shall use a (sometimes abbreviated) title of the paper, followed by the relevant page or pages of the version reprinted in OF. Bibliographical details of the papers can be found in the list of References at the end of this article. I refer to Fischer's introductory essay as 'Introduction'.

${ }^{2}$ In order to avoid irrelevant objections, the Fixity Principle should probably be formulated in a way that restricts it to so-called 'hard' facts about the past. (See, for example, OF, pp. 120, 126, 186, 199.) Unfortunately, I do not have space to discuss Fischer's very important arguments that the restriction to 'hard' facts does not vindicate an Ockhamist version of compatibilism about divine foreknowledge and human freedom.
} 
compatibilism concerning human freedom and divine foreknowledge (the principal topic of Our Fate), but also versions of compatibilism concerning freedom and causal determinism. These might collectively be called versions of 'altered-past compatibilism', using this term in a sense that is broader than its standard usage. ${ }^{3}$

\section{The Fixity Principle: dispensing with transfer principles}

One of Fischer's principal contentions is that although some incompatibilist arguments that are driven by the idea of the fixity of the past rely on what are known as 'transfer principles' (of which I shall say more shortly), 'we can give versions of the argument for incompatibilism that do not rely explicitly or implicitly on any transfer principle'

('Introduction', p. 5). According to Fischer, a 'fixity' argument for incompatibilism can avoid this reliance by employing, as a premise in the argument, a version of the Fixity Principle such as the 'conditional' version or the 'possible-worlds' version to be discussed in $\S \S 3-4$ below. (See, for example, 'Introduction', pp. 5-6.)

I find Fischer's attitude to the role of transfer principles puzzling, however. For it seems to ignore the fact that - however controversial they may be - transfer principles play a crucial role in a type of argument for the Fixity Principle.

On the face of it, incompatibilist proponents of Fischer's Fixity Principle face a dialectical problem. For it appears that the compatibilist (at least what I am calling the altered-past compatibilist; I'll take this qualification for granted in what follows) will simply deny the Fixity Principle. There is, therefore, a danger of what Fischer has called a 'dialectical stalemate' (1994, p. 84), with incompatibilists simply insisting that the past puts a limitation on our abilities that is repudiated by the compatibilist.

One attempt to break this stalemate (as I see it) seeks to derive the Fixity Principle from a combination of two claims: one concerning our lack of 'direct' power over the past (a claim that, on the face of it, is less controversial than the Fixity Principle), and the other a

\footnotetext{
${ }^{3}$ In particular, David Lewis's 'local-miracle compatibilism', as it is standardly called, is a version of 'altered-past compatibilism' in my sense. This is because his local-miracle compatibilism involves the claim that, under determinism, the relevant worlds in which I act otherwise are worlds that involve a difference in the past immediately before my action, even though they do not involve a difference in the remote past before my action (Lewis 1981). Fischer's Fixity Principle, however, makes no discrimination between the remote past and the immediate past (cf. Mackie 2003, §6). The term 'altered-past compatibilism' is taken from Horgan 1985, who uses it in a narrower sense, one that excludes Lewis's 'local-miracle compatibilism'.
} 
'Transfer Principle' to the effect that our lack of direct power over the past is 'transferred' to a lack of power over anything that would require a difference to the past.

One such argument employs a 'Transfer Principle' quoted by Fischer: 'if an agent has it in his power to bring it about that $p$, and if $p$ entails $q$, then the agent has it in his power to bring it about that $q$ ' (OF, pp. 117, 166). When combined with the principle that no agent has it in his power to bring it about that $q$ where $q$ is the negation of a true proposition stating that some past state of affairs obtained, this Transfer Principle delivers the conclusion that if an agent's doing $Y$ at $t$ is inconsistent with the truths about the past relative to $t$, the agent does not have it in his power to do $Y$ at $t$. And this conclusion is a version of Fischer's Fixity Principle.

This 'transfer argument' for the Fixity Principle - which space does not permit me to spell out in detail here - is highly contentious. ${ }^{4}$ But when Fischer appears to imply that, in the face of objections to the argument, incompatibilists may simply help themselves to the argument's conclusion (the Fixity Principle) without attempting to derive it from other premises (e.g., 'Scotism', pp. 60, 65; 'Introduction', p. 5), this looks suspiciously like an attempt to gain the advantages of theft over honest toil. ${ }^{5}$

As we shall see, though ( $\S 4$ below), Fischer does, in some of his writings, give an alternative positive argument for a version of the Fixity Principle, thus providing, in effect, a response to my complaint.

\section{The Fixity Principle: beyond the conditional formulation}

When arguing for the dispensability of transfer principles to the incompatibilist's argument, Fischer's initial proposal was that the incompatibilist may appeal directly to a 'conditional' version of the Fixity Principle, represented by the following:

\footnotetext{
${ }^{4}$ The 'transfer argument' that I have outlined here has obvious affinities with versions of the Consequence Argument (for the incompatibility of free will and causal determinism) that rely on a combination of a claim about our lack of power over the past and laws of nature with the claim (arrived at via an application of a Transfer Principle) that we lack power over anything that is entailed by the combination of the past and laws of nature. For more on the comparison, see Mackie 2003. See also Fischer, 'Scotism', and Fischer 1994, Chs 1-3.

${ }^{5}$ Fischer does not appear to regard the appeal to the Transfer Principle as a strategy (even a failed strategy) for arguing for the principle of the Fixity of the Past. Instead, when Fischer discusses incompatibilist arguments that employ the Transfer Principle, he treats them as relying on (rather than attempting to support) the Fixity Principle. (See 'Introduction', pp. 2-5; 'Scotism', pp. 54-60; 'Foreknowledge, Freedom, and Fixity', pp.117-18; 'Engaging with Pike', p. 166.) For the reasons explained in the text, I find this attitude puzzling.
} 
(FP) For any action $Y$, agent $S$, and time $T$, if it is true that if $S$ were to do $Y$ at $T$, some fact about the past relative to $T$ would not have been a fact, then $S$ cannot at (or just prior to) $T$ do $Y$ at $T$. ('Introduction', p. 5) ${ }^{6}$

(FP) is, however, notoriously vulnerable to objections based on alleged counterexamples involving backtracking counterfactuals. ${ }^{7}$ One of the most interesting features of Fischer's treatment of the Fixity of the Past is his response to these objections.

Fischer presents, as a typical instance of an apparent counterexample to (FP), the case of the Salty Old Seadog:

The salty old seadog always checks the weather at 9:00 am . . He calls the weather service. If they tell him the weather will be fair at noon, he always goes sailing at noon. And if they tell him the weather won't be fair at noon, he never goes sailing at noon. This is his stable, reliable mindset and disposition with regard to sailing . . .

We make no assumptions about the existence of God or causal determinism . . . It is just prior to noon, and this morning the seadog was told that the weather would be horrible at noon. He is his usual self, and he decides not to go sailing at noon. But can he nevertheless go sailing at noon? It seems that he has it in his power to do so; after all, he is not coerced, manipulated electronically, hypnotized, and so forth, and we are not assuming the existence of an omniscient God, or that causal determinism obtains. So some would insist that the seadog can go sailing at noon.

Now it also seems that the following backtracking conditional is true in the example:

[(B1)] If the seadog were to go sailing at noon, then the weatherman would have told him at 9:00 am that the weather would be fair at noon.

But if so, then we have a counterexample to (FP).

('Introduction', p. 10, but with Fischer's conditional $(\mathrm{C} 1)$ relabelled as '(B1)' ('B' for 'backtracker'). Cf. 'Power over the Past', pp. 103-104.)

As Fischer notes, the incompatibilist could attempt to resist the alleged counterexample to (FP) (p. 11). However, Fischer argues that the incompatibilist need not do so. The incompatibilist can concede, at least for the sake of argument, that this example does refute the 'conditional' version of the Fixity Principle ((FP)). No matter, for the example does not refute a different, 'possible-worlds' formulation of the Fixity Principle, namely (FP*):

\footnotetext{
${ }^{6}$ Similar formulations are to be found in many of the papers reprinted in OF, as well as in Fischer 1994. See note 2 above for the possibility of restricting the principle to 'hard' facts about the past.

${ }^{7}$ See, for example, 'Power over the Past', 'Foreknowledge, Freedom, and Fixity', and the 'Introduction' to OF.
} 
(FP*) An agent $S$ has it in his power at (or just prior to) $T$ in possible world $w$ to do $X$ at $T$ only if there is a possible world $w^{*}$ with the same past as that of $w$ up to $T$ in which $S$ does $X$ at $T$. ('Introduction', pp. 6,11$)^{8}$

Why so? Because the proponent of $\left(\mathrm{FP}^{*}\right)$ can insist that, if the 'can-claim' is true in the case of the Salty Old Seadog, this is because there is some possible world (a 'past-matching possible world') that is in accord with (FP*). This would, of course, have to be a world in which the seadog acts out of character - one in which, in spite of the warning at 9:00 am of foul weather, he nevertheless breaks the habit of a lifetime and decides to go sailing. However, it appears to be consistent with this to claim that the closest possible worlds in which the seadog goes sailing at noon are ones in which he does not act out of character, but instead acts in accord with his settled dispositions, against the background of a different past. And if the closest possible worlds are of this type, the backtracking counterfactual (B1) will be true, according to a widely accepted account of the truth-conditions of counterfactuals ( $\mathrm{p}$. $11)$.

Fischer's ingenious argument thus appears to allow the (incompatibilist) proponent of the Fixity of the Past principle to sidestep the 'backtracking' problems to which the conditional version of the principle is vulnerable.

Even if Fischer is right about this, this move on the part of the incompatibilist from (FP) to (FP*) is, so far, merely a defensive one. ${ }^{9}$ Fischer argues, however, that the incompatibilist can go further. Building on examples such as that of the Salty Old Seadog, Fischer maintains that there is a positive argument for the Fixity of the Past principle, in the form of (FP*), based on considerations of practical rationality.

Before considering this further argument, though, we can note an interesting question raised by Fischer's Seadog example. It is granted, by incompatibilist and compatibilist alike, that the relevant 'can' claim is true, and hence that the seadog has, in the actual world, the ability to go sailing at noon. It is also granted, by incompatibilist and compatibilist alike, that there is a possible world corresponding to the backtracking counterfactual (B1) - call it the 'B-world', in which the seadog goes sailing at noon. ${ }^{10}$ The question is: when, in the B-world (the world with a different past from that of the actual world), the seadog goes sailing, is he,

\footnotetext{
${ }^{8}$ Again, similar formulations of Fischer's 'possible-worlds' version of the Fixity Principle can be found in many papers in OF, as well as in Fischer 1994. See also note 2 above.

${ }^{9}$ As Fischer himself emphasizes: e.g., in 'Power over the Past', p. 113.

${ }^{10}$ Of course, if there is one B-world, there will be many. But for simplicity I'll ignore that fact, and speak of 'the B-world'.
} 
in the B-world, exercising the ability to go sailing at noon that he actually has? As far as I am aware, Fischer does not explicitly address this question. However, I believe (although I cannot argue fully for this here) that the answer of Fischer's incompatibilist should be 'No'. For one thing, if, in going sailing in the B-world, the seadog were exercising an ability to go sailing at noon that he actually has, it would seem strange to regard the seadog's action in the B-world as irrelevant to the 'can-claim' concerning that ability, as the incompatibilist is committed to doing. It appears, then, that we have the following result. Both compatibilist and incompatibilist agree that the seadog actually has (at or just before noon) the ability to go sailing at noon, even though he does not actually exercise that ability. Both compatibilist and incompatibilist agree that the B-world is a possible world in which the seadog goes sailing at noon. But whereas the compatibilist thinks that the seadog's action in the B-world is (or at least may be) an exercise of his actual ability to go sailing at noon, the incompatibilist denies this. I shall return to this point in the next section.

\section{Practical Reasoning and the Fixity of the Past}

If the incompatibilist simply insists, without argument, on the truth of the Fixity Principle (FP*), this may be regarded as, if not begging the question, then at least dialectically impotent in the debate against the compatibilist. In effect, the problem of the 'dialectical stalemate' mentioned in $\S 2$ above threatens to recur.

However, Fischer claims that this situation can be remedied: 'it is at least plausible that rejecting $\left(\mathrm{FP}^{*}\right)$ would lead to unacceptable consequences for practical reasoning. Thus there is a plausibility argument for accepting $\left(\mathrm{FP}^{*}\right)$. . . that does not depend on a prior acceptance of incompatibilism' ('Introduction', p. 18).

Fischer's 'practical rationality' argument appeals to cases with the same structure as that of the Salty Old Seadog. He employs an example taken from The Metaphysics of Free Will:

Consider the example of the Icy Patch. Sam saw a boy slip and fall on an icy patch on Sam's sidewalk on Monday. The boy was seriously injured, and this disturbed Sam deeply. On Tuesday, Sam must decide whether to go ice-skating. Suppose that Sam's character is such that if he were to decide to go ice-skating at noon on Tuesday, then the boy would not have slipped and hurt himself on Monday.

('Introduction', p. 18, quoting Fischer 1994, p. 95) 
We fill out the example so as to make it plausible that, according to both incompatibilist and compatibilist, Sam is able to decide to go, and to go, ice-skating on Tuesday. ${ }^{11}$ And - as in the case of the Seadog - we can assume that both incompatibilist and compatibilist accept the truth of the relevant backtracking conditional. Yet - and this is the crucial point - it would clearly be irrational for Sam to take into account, when making up his mind whether to go skating on Tuesday, the truth of this backtracking conditional - that is, the fact that, if he were to decide to go skating, the terrible accident would not have occurred on Monday. And this, Fischer claims, is an embarrassment to the compatibilist, who rejects (FP*). To quote at length from Fischer:

If we accept (FP*), we can say what we should say about practical reasoning in a case such as Icy Patch. Intuitively, what Sam can do on Tuesday is to add to the given past (in which the terrible accident did indeed take place on Monday). So any reasons flowing from the non-occurrence of the accident on Monday are just irrelevant to Sam. But how exactly can one embrace this obvious point, if one rejects (FP*)? . . Having abandoned (FP*), why isn't Icy Patch an example in which Sam has access on Tuesday to a possible world in which the accident didn't happen on Monday? More specifically, given a rejection of (FP*), why can't Sam bring it about on Tuesday - simply by deciding to go ice-skating - that the world did not contain the accident on Monday?

('Introduction', p. 19; bold emphasis mine)

Given a rejection of (FP*), nothing rules it out that in Icy Patch, Sam has access on Tuesday to a possible world in which the accident did not occur on Monday. . . But if this is so, why shouldn't Sam take this as a reason to decide to go ice-skating on Tuesday? If it is appropriate for Sam to take as relevant reasons that obtain in any world genuinely accessible to him at a time, then surely [if (FP*) is rejected] it is (or may well be) rational for him to decide to go ice-skating on Tuesday.

But ... this is a manifestly unacceptable result ...

('Introduction', pp. 20-21; bold emphasis mine)

Fischer's argument is as follows. Although both incompatibilist and compatibilist regard the 'B-world' of this example (a world in which Sam decides on Tuesday to go skating, and there is no previous accident on Monday) as possible, the incompatibilist regards it as 'inaccessible' to the deliberator, whereas the compatibilist (who denies (FP*)) seems committed to regarding it as 'accessible' to the deliberator. Given the principle (call it 'the Accessibility Principle') that it is appropriate to take into account, in one's practical

${ }^{11}$ According to the incompatibilist, who accepts $\left(\mathrm{FP}^{*}\right)$ (but not, of course, the compatibilist), the truth of the relevant 'can-claim' requires that there be a 'past-matching' world in which Sam knows on Tuesday of the accident on Monday, and yet acts out of character and decides to go skating in spite of this. 
reasoning, reasons that obtain in any world that is 'accessible' (see the second quotation above), the compatibilist is in an embarrassing position, since it is manifestly inappropriate for the deliberator (Sam) to take the reasons that obtain in the B-world into account.

Fischer's 'practical rationality' argument for $\left(\mathrm{FP}^{*}\right)$ rests on two crucial claims. One is the Accessibility Principle. The other is that the compatibilist is committed to accepting (or at least has no good reason to deny) that the B-world is 'accessible' to the deliberator, even though the B-world has a different past from the actual world.

I shall now challenge this combination of claims. I shall argue that either it is reasonable for the compatibilist to regard the B-world as inaccessible to the deliberator, or Fischer's Accessibility Principle is cast into doubt.

Fischer does not, as far as I am aware, explain exactly what it means to say that a world (or scenario) is 'accessible' (in the relevant sense) to an agent. He does suggest, though, that if a world is 'accessible' to an agent (in the relevant sense), then the agent can bring it about that the world obtains (or is actual). (See the first quotation above.) Put in these terms, Fischer's claim is that whereas the incompatibilist denies that the agent can bring it about that the B-world obtains, the compatibilist is committed to asserting (or at least has no obvious reason to deny) that the agent can bring it about that the B-world obtains.

But how is Fischer to justify this claim about the compatibilist? One argument for this claim would appeal to the following 'Transfer (of Power) Principle':

(T) If $S$ can bring it about that $p$, and if it were the case that $p$, it would be the case that $q$, then $S$ can bring it about that $q$.

Given (T), one could argue as follows, using two premises ((1) and (2)) that the compatibilist accepts:

(1) Sam can (on Tuesday) bring it about that he decides (on Tuesday) to go ice-skating.

(2) If Sam were to decide (on Tuesday) to go ice-skating, the terrible accident would not have occurred on Monday.

Therefore:

(3) Sam can bring it about that the terrible accident did not occur on Monday.

Obviously, however, Fischer cannot appeal to this argument. For Fischer's incompatibilist must deny that this argument is valid, since he accepts its premises but denies its conclusion. By the same token, Fischer's incompatibilist is committed to rejecting the Transfer Principle (T). But if (T) can be rejected by the incompatibilist, why should the compatibilist be 
committed to it? Moreover, as we have seen ( $\$ 2$ above), Fischer has committed himself to the project of defending incompatibilism without appeal to Transfer Principles. It would therefore be inconsistent for him to appeal, in his argument for (FP*), to versions of the Transfer Principle (including (T)).

A more promising strategy, however, (for arguing that the compatibilist should treat the B-world as 'accessible') is for Fischer to characterize the 'accessibility' of a possible world in terms of the exercise of the agent's abilities, along the following lines:

Where an agent $S$ is deliberating about whether to do $Y$, and where $S$ can do $Y$, any possible world (or scenario) in which the agent exercises her ability to do $Y$ (the ability corresponding to the 'can-claim') is, in the relevant sense, 'accessible' to the agent.

It does seem that, in this sense of 'accessible', the compatibilist should say that the B-world, in which the accident did not occur on Monday, is accessible to Sam as he deliberates on Tuesday about whether to go skating, although the incompatibilist should not. For according to my argument in $\S 3$ above, it seems that while both incompatibilist and compatibilist agree that the B-world is possible, and that it is a world in which Sam does something that he actually has the ability to do, the compatibilist should hold that the B-world is one in which Sam exercises this ability, whereas the incompatibilist should not.

So far, so good. The trouble is, however, that if accessibility is characterized in these terms, Fischer's Accessibility Principle becomes suspect. ${ }^{12}$

For suppose that some possible world in which the agent $S$ exercises her ability to do $Y$ is a world of which $S$ can be rationally certain that it will not be actual (and will not be actual even if she does do $Y$ ). Fischer's Accessibility Principle, as we are now interpreting it, tells $S$ that she should nevertheless take, as relevant to her actual decision whether to do $Y$, the reasons that obtain in that world. But in that case, the Accessibility Principle clearly gives the wrong answer. How could rationality require $S$ to take into account, in deciding whether to do $Y$, a world that she can be certain will not be actual even if she does $Y$ ? Yet that is exactly what the Accessibility Principle dictates.

Moreover, this is, of course, precisely the situation in which Sam (or at least an appropriately knowledgeable Sam) finds himself in the example of Icy Patch, according to

\footnotetext{
${ }^{12}$ My challenge to Fischer's Accessibility Principle is distinct from two others: an appeal to causal decision theory, and André Gallois' (2009) principle of the fixity of reasons. Although Fischer recognizes both of these challenges, he complains that they seem 'ad hoc'. (See Fischer 1994, pp. 102-104, and Fischer and Pendergraft 2013, §4.)
} 
the compatibilist's construal of the example. Sam is deliberating, on Tuesday, whether to go skating on Tuesday. He has (and believes that he has) the ability to go skating on Tuesday. (Let us refer to this as 'the ability to go skating ${ }_{\mathrm{T}}$ '.) He believes that there is a possible world, the B-world, in which he goes skating on Tuesday, but there is no terrible accident on Monday. Moreover (if Sam is a compatibilist), Sam believes that the B-world is one in which he exercises his ability to go skating ${ }_{\mathrm{T}}$. Nevertheless, Sam can be rationally certain, on Tuesday, that the B-world will not be actual (and will not be actual even if he exercises his ability to go skating $\mathrm{T}_{\mathrm{T}}$ ). For (whether he is a compatibilist or an incompatibilist) he knows that whatever he can do, anything that he will do will be an extension of the actual past. And the actual past on Tuesday includes, as he is aware, the accident on Monday. Given all this, Sam would obviously be crazy to take the fact that the accident does not occur on Monday in the B-world, plus the fact that the B-world is one in which he exercises his ability to go skating ${ }_{\mathrm{T}}$, as a reason for going skating on Tuesday. So he would obviously be crazy to follow the Accessibility Principle!

Now, of course, the incompatibilist will presumably say that, since Sam can be rationally certain that the B-world will not be actual, he should not regard it as a world in which he exercises his ability to go skating $\mathrm{T}_{\mathrm{T}}$, and hence should not regard it as a world that satisfies the definition of 'accessible' that is relevant to the Accessibility Principle.

According to the incompatibilist, there is nothing wrong with the Accessibility Principle; rather, the problem is with the compatibilist's view about which worlds are those in which Sam exercises his ability, and thus about which worlds satisfy the Principle's definition of 'accessibility'. But to insist on this, in the context of the current debate, would be to beg the question against the compatibilist.

If I am right, Fischer's 'practical rationality' argument does not, after all, succeed in breaking a dialectical stalemate over the acceptability of the incompatibilist's Fixity Principle (FP*). Nevertheless, this does not undermine the importance of Fischer's ingenious and provocative discussion of these issues. ${ }^{13}$

\author{
Department of Philosophy \\ University of Nottingham \\ Nottingham NG7 2RD \\ UK
}

penelope.mackie@nottingham.ac.uk

\footnotetext{
${ }^{13}$ Thanks to Robert Frazier for helpful discussion of drafts of this paper.
} 


\section{References}

Fischer, J. M. 1984. 'Power over the Past'. Pacific Philosophical Quarterly, 65: 335-50. Reprinted as Chapter 5 of Fischer 2016.

Fischer, J. M. 1985. 'Scotism'. Mind, 94: 231-43. Reprinted as Chapter 2 of Fischer 2016.

Fischer, J. M. 1994. The Metaphysics of Free Will: An Essay on Control. Oxford: Blackwell.

Fischer, J. M. 2011. 'Foreknowledge, Freedom, and the Fixity of the Past'. Philosophia, 39: 461-74. Reprinted as Chapter 6 of Fischer 2016.

Fischer, J. M. 2016. Our Fate: Essays on God and Free Will. New York: Oxford University Press.

Fischer, J. M. and Pendergraft, G. 2013. 'Does the Consequence Argument Beg the Question?' Philosophical Studies, 166: 575-95.

Fischer, J. M., Todd, P., and Tognazzini, N. A. 2009. 'Engaging with Pike: God, Freedom, and Time'. Philosophical Papers, 38: 247-70. Reprinted as Chapter 9 of Fischer 2016.

Gallois, A. N. 2009. 'The Fixity of Reasons'. Philosophical Studies, 146: 233-48.

Horgan, T. 1985. 'Compatibilism and the Consequence Argument'. Philosophical Studies, 47: $342-45$.

Lewis, D. 1981. 'Are We Free to Break the Laws?' Theoria, 47: 113-21. Reprinted in Lewis, Philosophical Papers, Volume 2 (Oxford University Press, 1986).

Mackie, P. 2003. 'Fatalism, Incompatibilism, and the Power to do Otherwise'. Noûs, 37: 672-89. 